\title{
A Pilot Study: Association between Minor Physical Anomalies in Childhood and Future Mental Problems
}

\author{
Helen Cheng ${ }^{1}$, Cheng-Chen Chang ${ }^{1,2}$, Yue-Cune Chang ${ }^{3}$, Wen-Kuei Lee ${ }^{4}$, and Ruu-Fen Tzang ${ }^{5,6} \bowtie$ \\ 1'Department of Psychiatry, Changhua Christian Hospital, Changhua, Taiwan \\ ${ }^{2}$ Institutes of Medicine, Chung Shan Medical University, Taichung, Taiwan \\ ${ }^{3}$ Department of Mathematics, Tamkang University, Taipei, Taiwan \\ ${ }^{4}$ Department of Psychiatry, Beitou Branch, Tri-Service General Hospital, Taipei, Taiwan \\ ${ }^{5}$ Department of Psychiatry, Mackay Memorial Hospital, Taipei, Taiwan \\ ${ }^{6}$ Department of Health Care Management, National Taipei University of Nursing and Health Sciences, Taipei, Taiwan
}

Objective This study aims to investigate association between early recognizable minor physical abnormality (MPA) during childhood is associated with mental health problems in young adults.

Methods In 1984, 169 preschool children in central Taiwan underwent a detailed physical examination for subtle abnormalities (MPA). Fourteen years later, the Brief Symptom Rating Scale (BSRS) and Chinese Health Questionnaire (CHQ) were used to measure specific psychiatric symptoms.

Results There is an association between MPA during childhood and adult characterized with interpersonal sensitivity, anxiety, depression and paranoid mental health symptoms.

Conclusion The signs of childhood MPA can be easily identified and should be regarded as risk factors when predicting mental disorder. Mental health professionals should consider MPAs as important signs for possible development of emotional problems.

Psychiatry Investig 2014;11(3):228-231

Key Words Minor physical anomalies, Psychiatric symptom.

\section{INTRODUCTION}

Minor physical anomalies (MPA) are neurodevelopmental markers, which manifest as unusual morphological features on the face and body. MPAs during childhood can be regarded as a predictor or risk of neurodevelopmental disorders because both the skin and brain are derived from the neuro-ectoderm during the first three months of fetal life. These minor anatomical anomalies may parallel early developmental defects of the central nervous system and may possibly stem from prenatal insults or congenital abnormality. ${ }^{1}$ The discrete signs of

Received: April 10, 2013 Revised: July 14, 2013

Accepted: July 17, 2013 Available online: July 21, 2014

$\triangle$ Correspondence: Ruu-Fen Tzang, MD

Department of Psychiatry, Mackay Memorial Hospital, Number 92, Sec. 2, Chung Shan N Road, Taipei 104, Taiwan

Tel: +886-2-28098249, Fax: +886-2-25433535

E-mail: rf.tzang@msa.hinet.net

(a) This is an Open Access article distributed under the terms of the Creative Commons Attribution Non-Commercial License (http://creativecommons.org/licenses/bync/3.0) which permits unrestricted non-commercial use, distribution, and reproduction in any medium, provided the original work is properly cited.
MPA, e.g., small head circumference, hypertelorism, malformed ears, high palate, epicanthus was found on children with Down's Syndrome, or congenital neurodevelopment disorder. ${ }^{2}$ According to literature review, children with autism, ${ }^{3-5}$ autism spectrum disorder, ${ }^{6}$ delayed speech, learning disabilities, mental retardation, ${ }^{7}$ hyperactivity, ${ }^{8}$ rebellious nature, destructive behaviour, criminality, ${ }^{9}$ living in an adverse family environment ${ }^{10}$ or idiopathic retardation, ${ }^{11}$ school failure, ${ }^{12}$ schizophrenia and autism, ${ }^{3}$ or some temperament problem ${ }^{13}$ had reported to have more signs of MPA than those children without such abnormalities.

MPAs are prevalent with an average of $15 \%$ of normal population experiencing some MPA ${ }^{11}$ and are easily measured by examination. Recent research further found a link between MPAs and schizophrenia or bipolar affective disorder ${ }^{14-16}$ and such association studies shed a light on early detection of the risks of schizophrenia by cross sectional study. But to date there have been no follow up studies investigating psychiatric problems in adults who had signs of MPA during childhood. This study intends to answer whether MPA can be regarded as early 
detection of the risks of mental problems by follow up study.

\section{METHODS}

\section{Participants}

As part of a yearly routine paediatric health examination, physicians from a local medical centre in central Taiwan took basic measurements, including height, weight, head girdle, and administered a physical examination. From the data collected from 1984 to 1998, we also assessed the presence of any minor physical anomaly (MPA), temperament, and activity level of 169 children, aged 5-6 years. We then followed up on the subject's psychiatric symptoms using Brief Symptoms Rating Scale (BSRS), Chinese Health Questionnaire (CHQ) to evaluate the subject's mental health and their persistence of MPA signs 14 years later. Of the original 169 subjects, only 84 could be traced. Subjects or the parents of the subjects were telephoned, and if they consented to the study, a structured questionnaire was sent to them by mail. Out of 84 questionnaires mailed, 55 (32.5\%) were returned.

\section{Minor Physical Anomalies measurement}

The 18-item Waldrop minor physical anomaly rating scale ${ }^{17}$ was used to measure six areas of the body for abnormalities, including head, eyes, ears, mouth, hands, and feet, on the 5-6 year old children in our study. Specifically, the 18 abnormalities included fine electric hair, hair whorls $\geq 2$, epicanthus, hyper (hypo)telorism, low seated ears, adherent ear lobes, malformed ears, asymmetrical ears, soft and pliable ears, high palate, furrowed tongue, tongue with rough and smooth spots, curved fifth digit, single transverse palmar crease (simian crease), middle finger longer than index finger, third toe $\geq$ second toe, partial syndactyly of the middle toes (webbed toes), big gap between the 1st and 2nd toes. Children who showed signs of the abnormality received a score of 1 , while those who did not received a score of 0 . Patients with total Waldrop scores above 3 were defined as the high MPA subgroup. Previous studies have shown good inter-rater reliability for the total Waldrop score (intra-class correlation coefficient $=0.59){ }^{18}$

\section{Brief Symptom Rating Scale}

Brief Symptom Rating Scale (BSRS) consists of 50 questions, which are used to detect 10 chief psychiatric symptoms including somatization, obsession, interpersonal sensitivity, depression, anxiety, hostility, phobia, paranoia, psychoticism, and additional symptoms. Based on discriminant analysis of the 10 dimensional scores, the rate of accurate classification for BSRS between psychiatric and non-psychiatric cases was 75.8\%, with a sensitivity of $66.7 \%$ and a specificity of $86.7 \%{ }^{19}$

\section{Chinese Health Questionnaire}

CHQ is an effective measurement for minor psychiatric disorders for physicians. The sensitivities of the CHQ-30 and CHQ-12 were found to be $76 \%$ and $78 \%$ respectively, while the specificity of both was $77 \% .^{20}$

\section{Statistical analysis}

Descriptive statistics were used to summarize basic demographic data $(n=55)$. Data are expressed as mean \pm standard deviation or percentages where appropriate. The student t-test was applied to assess the strength of the relationship between MPA and psychiatric symptoms (somatization, obsession, interpersonal sensitivity, depression, anxiety, hostility, phobia, paranoia, psychoticism, and additional symptoms). Differences were considered statistically significant at $\mathrm{p}<0.05$.

\section{RESULTS}

\section{Demographic characteristics}

We enrolled 55 young adults who had MPA when they were 5-6 years old, including $29(52.7 \%)$ males. The mean $( \pm S D)$ age of the adults was 19.49 years $( \pm 0.50)$ with $78.2 \%$ college graduates and $20.4 \%$ high school graduates (Table 1 ).

There is a significant relationship between children with a high MPA score $(\geq 3)$ to interpersonal sensitivity $(t=-3.13$, $\mathrm{p}=0.003)$, depression $(\mathrm{t}=-2.64, \mathrm{p}=0.011)$, anxiety $(\mathrm{t}=-2.82$, $\mathrm{p}=0.007)$, and psychoticism $(\mathrm{t}=-3.47, \mathrm{p}=0.001)$ as an adult $(\mathrm{Ta}-$ ble 2).

Intention to treat (ITT) by comparing the basic data be-

Table 1. Demographic data of 55 adults with MPA sign at childhood

\begin{tabular}{lcr}
\hline & $\mathrm{N}$ & $\%$ \\
\hline Gender & 29 & 52.7 \\
Male & 26 & 47.3 \\
Female & $19.49(0.50)$ & \\
Age, mean (SD) & & \\
Education status & 25 & 45.5 \\
College graduated & 18 & 32.7 \\
Technical college & 1 & 1.8 \\
Senior high school & 11 & 20.4 \\
Junior high school & & \\
Occupational state & 45 & 81.8 \\
Studying & 5 & 9.1 \\
Occupation & 2 & 3.6 \\
Military & 3 & 5.5 \\
Other & & \\
\hline
\end{tabular}

MPA: minor physical anomalies 
tween the returned and un-returned groups was performed, and there was neither a significant difference between the two groups nor the integrity of the sample (Table 3 ).

\section{DISCUSSION}

This study aims to confirm whether MPA during childhood can be linked to any specific psychiatric symptom as a young adult. We found a significant relationship between children with a high MPA score $(\geq 3)$ and psychiatric symptoms, including interpersonal sensitivity, anxiety, depression, and a tendency toward paranoid fourteen years later.

To date, there is no longitudinal study to explore the correlation between childhood MPAs and adult mental health problems. Our longitudinal study is helpful towards contributing more information toward hypothesis that children who show

Table 2. Relationship between psychiatric symptom to MPA score $\geq 3$

\begin{tabular}{lccccc}
\hline & $\mathrm{MPA} \geq 3$ & & $\mathrm{MPA}<3$ & $\mathrm{t}$ & $\mathrm{p}$ \\
\cline { 2 - 3 } \cline { 6 - 6 } Total & $\mathrm{M}(\mathrm{SD})$ & & $\mathrm{M}(\mathrm{SD})$ & & \\
Somatization & $2.21 \pm 2.36$ & & $2.97 \pm 2.81$ & -0.89 & 0.38 \\
Obsession & $3.79 \pm 2.46$ & & $5.36 \pm 3.78$ & -1.44 & 0.16 \\
Interpersonal & $1.71 \pm 1.54$ & & $4.03 \pm 3.63$ & -2.3 & $0.03^{*}$ \\
sensitivity & & & & & \\
Depression & $2.43 \pm 1.55$ & & $4.94 \pm 5.15$ & -2.64 & $0.01^{*}$ \\
Anxiety & $1.00 \pm 1.30$ & & $2.89 \pm 3.43$ & -2.824 & $0.003^{\dagger}$ \\
Hostility & $1.50 \pm 1.74$ & & $2.53 \pm 2.58$ & -1.37 & 0.18 \\
Phobia & $1.00 \pm 1.88$ & & $2.28 \pm 2.5$ & -1.73 & 0.09 \\
Paranoid & $1.14 \pm 1.17$ & & $3.19 \pm 3.01$ & -3.47 & $0.001^{\dagger}$ \\
Phychoticism & $1.23 \pm 1.54$ & & $2.25 \pm 2.62$ & -1.67 & 0.1 \\
Additional & $1.57 \pm 1.55$ & & $1.94 \pm 2.63$ & -0.49 & 0.62 \\
Introverted & $8.36 \pm 5.42$ & & $1.00 \pm 6.67$ & -0.82 & 0.42 \\
Extroverted & $16.64 \pm 3.13$ & & $16.92 \pm 4.73$ & -0.2 & 0.84 \\
Socialpathy & $3.86 \pm 2.18$ & & $4.05 \pm 2.21$ & -0.285 & 0.78 \\
CHQ & $1.21 \pm 1.58$ & & $2.24 \pm 2.49$ & -1.75 & 0.88 \\
\hline
\end{tabular}

${ }^{*} \mathrm{p}<0.05,{ }^{\dagger} \mathrm{p}<0.001$. MPA: minor physical anomalies, CHQ: Chinese Health Questionnaire

Table 3. ITT analysis of return and non-return adult with MPA

\begin{tabular}{llcc}
\hline & Return, N (\%) & Non-return, N (\%) & $\mathrm{p}$ \\
\hline MPA & & & \\
MPA $\geq 3$ & $14(26.90)$ & $28(27.5)$ & 0.945 \\
MPA $<3$ & $38(73.1)$ & $74(72.5)$ & \\
Sex & & & \\
Male & $29(52.7)$ & $68(59.6)$ & 0.395 \\
Female & $26(47.3)$ & $46(40.05)$ & \\
\hline
\end{tabular}

MPA: minor physical anomalies, ITT: intention to treat signs of MPA can be regarded as early detection of the risks of mental problems as other research studied. ${ }^{21}$ We suggest child mental health expertise to check MPA sign during routine child health examinations and providing parents of children with MPA with knowledge about child mental health is also important for reaching the goal of preventing mental illness formation during their early seeking interventional help process.

Definitely any kind of illness formation is originated from biologic risk plus pathologic environmental risk as previous research shows that a high MPA score coupled with family adversity is a significant predictor of criminality or problematic behavior. ${ }^{22}$ Because of study limitation, we are not aware how the risky environment factors influence the developmental process of children with MPA sign. In summary, further systemic study including risky environment factors and MPA sign would be needed in future.

This study has the following limitations. 1) Although ITT showed there was neither a significant difference between the two groups nor the integrity of the sample. But this study began by examining a total of 169 children with MPA, however, due to difficulties in tracking down the children eventually only 55 cases (32.5\%) returned the study questionnaire, leading to a potentially compromised generalization of our results. 2) There is no control group to compare whether really the children with MPA definitely will develop to an adult with psychiatric symptom. But this study is helpful to lead the clinician recognizing MPA at child psychiatric clinics and during child mental health screening is necessary for early recognition and treatment of psychiatric symptoms.

\section{REFERENCES}

1. Firestone P, Prabhu AN. Minor physical anomalies and obstetrical complications: their relationship to hyperactive, psychoneurotic, and normal children and their families. J Abnorm Child Psychol 1983;11: 207-216.

2. Rodier PM, Bryson SE, Welch JP. Minor malformations and physical measurements in autism: data from Nova Scotia. Teratology 1997;55: 319-325.

3. Campbell M, Geller B, Small AM, Petti TA, Ferris SH. Minor physical anomalies in young psychotic children. Am J Psychiatry 1978;135:573575.

4. Firestone P, Peters S. Minor physical anomalies and behavior in children: a review. J Autism Dev Disord 1983;13:411-425.

5. Hardan AY, Keshavan MS, Sreedhar S, Vemulapalli M, Minshew NJ. An MRI study of minor physical anomalies in autism. J Autism Dev Disord 2006;36:607-611.

6. Cheung C, McAlonan GM, Fung YY, Fung G, Yu KK, Tai KS, et al. MRI study of minor physical anomaly in childhood autism implicates aberrant neurodevelopment in infancy. PLoS One 2011;6:e20246.

7. Steg JP, Rapoport JL. Minor physical anomalies in normal, neurotic, learning disabled, and severely disturbed children. J Autism Child Schizophr 1975;5:299-307.

8. Firestone P, Peters S, Rivier M, Knights RM. Minor physical anomalies in hyperactive, retarded and normal children and their families. J Child 
Psychol Psychiatry 1978;19:155-160.

9. Raine A. Annotation: the role of prefrontal deficits, low autonomic arousal, and early health factors in the development of antisocial and aggressive behavior in children. J Child Psychol Psychiatry 2002;43: 417-434.

10. Kandel E, Brennan PA, Mednick SA, Michelson NM. Minor physical anomalies and recidivistic adult violent criminal behavior. Acta Psychiatr Scand 1989;79:103-107.

11. Ulovec Z, Skrinjaric I, Sosic Z, Szirovicza L, Jukic J. The prevalence of minor physical anomalies in mentally retarded children. Coll Antropol 2002;26:119-128.

12. Rosenberg JB, Weller GM. Minor physical anomalies and academic performance in young school-children. Dev Med Child Neurol 1973; 15:131-135.

13. Paulhus DL, Martin CL. Predicting adult temperament from minor physical anomalies. J Pers Soc Psychol 1986;50:1235-1239.

14. Franco JG, Valero J, Labad-Alquezar A. Minor physical abnormalities and clinical features in patients with schizophrenia spectrum disorders. Rev Neurol 2012;54:468-474.

15. John JP, Arunachalam V, Ratnam B, Isaac MK. Expanding the schizophrenia phenotype: a composite evaluation of neurodevelopmental markers. Compr Psychiatry 2008;49:78-86.

16. Trixler M, Tenyi T, Csabi G, Szabo R. Minor physical anomalies in schizophrenia and bipolar affective disorder. Schizophr Res 2001;52: 195-201.

17. Waldrop MF, Pedersen FA, Bell RQ. Minor physical anomalies and behavior in preschool children. Child Dev 1968;39:391-400.

18. Akabaliev VH, Sivkov ST. Internal consistency of Waldrop Physical Anomaly Scale in schizophrenic patients. Psychiatry Res 2007;150:8188.

19. Lee MB, Lee YJ, Yen LL, Lin MH, Lue BH. Reliability and validity of using a Brief Psychiatric Symptom Rating Scale in clinical practice. J Formos Med Assoc 1990;89:1081-1087.

20. Chong MY, Wilkinson G. Validation of 30- and 12-item versions of the Chinese Health Questionnaire (CHQ) in patients admitted for general health screening. Psychol Med 1989;19:495-505.

21. Pine DS, Shaffer D, Schonfeld IS, Davies M. Minor physical anomalies: modifiers of environmental risks for psychiatric impairment? J Am Acad Child Adolesc Psychiatry 1997;36:395-403.

22. Arseneault L, Tremblay RE, Boulerice B, Seguin JR, Saucier JF. Minor physical anomalies and family adversity as risk factors for violent delinquency in adolescence. Am J Psychiatry 2000;157:917-923. 